\title{
An Analysis of the Application of Flip Class in College Second Foreign Language Teaching
}

\author{
Jiaxing Kong ${ }^{1 *}$, Xiaohan Zhang ${ }^{2}$, Mengjia $\mathrm{Gu}^{3}$ \\ ${ }^{1}$ Nanjing Normal University, Nanjing City 210024, Jiangsu Province, China. E-mail: 1347312338@qq.com \\ ${ }^{2}$ Shandong Jiaotong University, Jinan City 250357, Shandong Province, China \\ ${ }^{3}$ Peking University, Haidian District 100871, Beijing, China
}

\begin{abstract}
With the parallel connection between China and the international economy and culture, the number of foreign students who are imported and exported in my country is increasing, and they are also increasingly connected in various aspects such as cultural life and economic development. Therefore, choosing to learn a second foreign language in universities has also become a trend. In addition to the lack of second-language majors in most high-efficiency, under the traditional education model of our country, learning second-language languages has many disadvantages. For example, there is a lack of language communication scenarios, and grammar learning is more than oral practice. In order to break this traditional and inherent learning model and provide college students with more opportunities for situational communication and practice, the teaching model of flipping classrooms has been introduced into classrooms by more and more universities.
\end{abstract}

Keywords: Flipped Classroom; Second Foreign Language Teaching; Applied Research

\section{Introduction}

The characteristics of college students are openness, freedom, strong thinking logic ability, wide acceptance range, and strong self-learning ability. The introduction of flipping classrooms is mainly based on the characteristics of college students. Through the teaching mode of flipping classrooms, student's interest and autonomy are stimulated ${ }^{[1,2]}$. Flipping the classroom is a new type of classroom teaching model, which is mainly to transform the traditional model based on teachers into a new learning mode based on students, giving students more and more free learning space.

\section{Definition and characteristics of flipped classroom}

\subsection{Definition of flip class}

Flipping the classroom is also called upside-down classroom, which mainly refers to throwing away the fixed thinking and transferring the initiative of learning from the teacher to the student. Students can think and learn more autonomously and independently, instead of passively receiving what the teacher teaches. The core of flipping the classroom is to allow students to find the fun of learning on their own, so as to actively learn ${ }^{[3]}$. In the classroom, teachers spend most of their time with students to complete their studies, students can fully learn according to their own situation, and can learn from each other and answer each other, form a learning framework that is better than their own and develop the habit of independent learning and answering questions, with less effort.

\subsection{Features of the flipped classroom}

In college second foreign language education, the flipped classroom has the following characteristics: Firstly, the flipped classroom is mainly short and clear themed teaching videos, the characteristics of the video are refinement and clarity, generally only a few minutes, longer than a dozen minutes, the control knowledge points are quite targeted, suitable for students to self-learn according to their own situation. And the classification is clear, the theme is clear, it is very convenient to search and watch at any time, the time is short, it will not make the students feel long and bored, and there will be no situation where too many knowledge points need to be found. Second, the video teaching content of the flipped classroom is very clear and accurate, for example, Salman Khan is a famous American educator, this professor's video is not only concise, but also features that in the video, students can only see the teacher's hands and textbooks, and there are no other extras that will distract students. Students learn through Professor Salman Khan's video even more concentrated than in class. In addition, this model will make students feel that the professor is not far away, even like face-to-face and the professor used a concise and generous video screen to draw the students

Copyright (C) 2020 Jiaxing Kong et al.

doi: 10.18282/1-e.v9i2.1407

This is an open-access article distributed under the terms of the Creative Commons Attribution Non-Commercial License

(http://creativecommons.org/licenses/by-nc/4.0/), which permits unrestricted non-commercial use, distribution, and reproduction in any medium, provided the original work is properly cited. 
closer, creating a relaxed atmosphere. And some students absorb knowledge slowly, often failing to keep up with the teacher's rhythm, which will lead to inferiority, frustration, and inability to keep up with the progress, and eventually lose interest in learning. In the teaching mode of flipping the classroom, students can prepare and review according to their own situation, teachers can also answer questions online at any time, effectively solving the situation of the students' inconsistent learning progress. Guided by the teachers, the students conduct self-learning according to their own situations and effectively form their own learning rhythm. Fourth, the teaching model of flipping classroom is more convenient for students to review the knowledge they have learned. The small video of flipping classroom can not only effectively and clearly explain the knowledge points, students can also conduct selfexamination to understand the content of their own knowledge, and review again according to their own knowledge.

\section{Model and process of flipping the classroom}

\subsection{Flip the classroom model}

The teaching mode of flipping the classroom is mainly based on refined, accurate, targeted, and knowledge-rich videos. Teachers can download online or record by themselves ${ }^{[4]}$. Choosing excellent videos can not only greatly reduce the energy and time of teachers, but also allow students to contact more lecturers to view and solve problems from different angles and different aspects. At the same time, students are also understanding and mastering the importance of information gathering in learning in the flipped classroom. When using flipped classroom video teaching, although the existing video greatly saves the teacher's energy, But likewise, teachers should guide students to learn according to the actual situation of their classmates, and classify and sort various kinds of essence teaching videos on the Internet, whether they are self-contained or non-systematic, and reprocessed to become the best classroom material for students to learn repeatedly, to ensure that the content of the video is consistent with the course. In the study of a second foreign language in a university, teachers can arrange pre-lesson preparation tasks for students, organize and summarize the various problems encountered by students during preparation, and produce more targeted teaching videos. For students with different class learning speeds, teachers can divide the content learned in the classroom into multiple stages and multiple videos of multiple knowledge points, which can be of great help to the students to preview, review and review the knowledge points.

\subsection{Process of flipping the classroom}

Flipping the class starts with selecting or recording a video. When selecting video materials, teachers should determine the actual situation of all students in the class, do a good job of categorizing and summarizing, clarifying knowledge points, and consolidating after-school exercises to form a complete knowledge point learning and review system. The second is to conduct feedback and evaluation after class. Flipping the classroom pays great attention to communication, and communication is also very important in the study of university foreign languages, especially second foreign languages. The students' feedback and evaluation of the teachers are of great significance. The teachers can learn more about the students' abilities, levels, qualities, preferences and aspirations, and participate in the discussion among the students. This not only guides students to review and discuss what they have learned, but also improves the level of teacher selection and organization. Third, teachers should master balance and create connections in short videos with clear knowledge points, and establish an overall learning outline and structure for students.

\section{The development and application of flip class in second foreign language}

\subsection{Development of flipping the classroom}

The flipped classroom was originally filmed by teachers in the 21 st century during the teaching process and uploaded to the Internet to provide opportunities for other students to learn. Because of its clear knowledge points, accurate content, short and precise and other advantages, it has developed rapidly, which has a huge impact on the traditional teaching mode ${ }^{[5]}$. Flipping the classroom can not only reduce teachers' teaching pressure, give teachers more energy and time, but also quickly stimulate students' interest. Due to the great advantages of flipped classrooms, flipped classrooms have been questioned, but they are still developing rapidly around the world and are popular in a short time. There are already many successful examples of flipping classrooms in my country. For example, in the second foreign language teaching, teachers use the flipped classroom teaching mode to change the traditional classroom, replace the tables and chairs with sofas, and play soothing music, teachers use tablets to teach, which makes students feel very comfortable and relaxed. In addition, for our country, especially in areas where teachers are weak, flipping the classroom is of great significance, giving students equal opportunities to learn, using the flipped classroom teaching model. In addition, for our country, especially in areas where teachers are weak, flipping the classroom is of great significance, giving students equal opportunities to learn, using the flipped classroom teaching model, students can study the courses of famous professors in the whole country and even the world, which is of great significance to the second foreign language that lacks environment and foundation.

\subsection{Problems with flipping the classroom}

Compared with traditional teaching, flipping the classroom has great advantages, but there are also certain problems. For students, the teaching mode of flipping the classroom requires students to be proactive in their learning, and they can self-learn according to the guidance of the teacher and build their own learning framework according to their own situation. For teachers, it is necessary to guide according to the situation of different students, and to guide students to learn according to their own classroom conditions. To classify and organize various kinds of essence teaching videos on the Internet and processing to become the most suitable flipped classroom material for students to repeat learning, to ensure that the content of the video is consistent with the course, which also has higher requirements for teachers. In addition, teachers are required to quickly switch between the traditional teaching model and the flipped classroom teaching model to change the teacher from an active role to a passive role, which is very 
difficult for many teachers to adapt ${ }^{[6]}$.

\subsection{Application of flip class in second foreign language}

Taking the university's second foreign language as an example, in the teaching mode of flipping the classroom, teachers should always pay attention to the student-centered teaching concept and maintain equal communication with students. Regarding the problems faced by the second foreign language in the current domestic teaching environment, teachers should choose learning videos that are mainly spoken, communication and situational, so that students can actually feel the learning atmosphere of the second foreign language. To learn how to use the grammar and sentences that teachers have taught in the classroom through observation and practice, students should strengthen discussions and engage in situational dialogues with each other to achieve the purpose of learning and mastering. Teachers should give guidance and supplement to the students' learning situation, strengthen the theoretical explanation of grammar and phrases, summarize the students' learning problems, and improve the teaching quality of the flipped classroom ${ }^{[7]}$.

\section{Conclusion}

Regarding the current short board of university second foreign language teaching, flipping the classroom teaching model has great advantages, but there are pros and cons to any of the models. Teachers should make full use of the advantages of flipping the classroom to innovate, fill in the second foreign language teaching short board in a greater sense, enrich the learning materials of students, and improve the overall quality and level of students.

\section{References}

1. Zhang M. Research on the application of flipped classroom in college English teaching (in Chinese). Talent 2020 ; (13): 54.

2. Zhao X. The application of flip classroom teaching mode in college English teaching-Taking Xinzhou Teachers College as an example (in Chinese). Modern Communication 2020; (08): 6-9.

3. Zheng R. A preliminary study of the application of "Flip Class" in the second foreign language (Japanese) teaching-Taking standard Japanese elementary (Volume 2) lesson 28 as an example (in Chinese). Journal of Jiamusi Vocational College 2019; (05): $182-183$.

4. Guo J. Research on the application of flip class in the teaching of second foreign languages in universities (in Chinese). Journal of Jiangxi Vocational and Technical College of Electricity 2018; 31(05): 49-50.

5. Xu X. The application of flipped classroom in college foreign language teaching (in Chinese). Journal of Harbin Vocational and Technical College 2018; (01): 142-144.

6. Jiang D. Analysis of the application of the flipped classroom teaching model of micro-classes in college foreign language teaching (in Chinese). Course Education Research 2017; (05): 148.

7. Ma J. Application of the flipped classroom concept in college foreign language teaching (in Chinese). Journal of Jilin Radio \& TV University 2017; (01): 82-83. 